\title{
UBER E DIREITO TRIBUTÁRIA: UMA ANÁLISE TRIBUTÁRIA DESTA NOVA TECNOLOGIA
}

\author{
UBER AND TAX LAW: AN ANALYSIS TAX THIS NEW TECHNOLOGY
}

\author{
1 Bruno Bianco Leal \\ ${ }^{2}$ Thiago Mafra Tancredo
}

\begin{abstract}
RESUMO
As novas tecnologias que são desenvolvidas trazem maior facilidade ao cidadão, mas podem trazer prejuízos, como é o caso do aplicativo Uber que está causando transtornos e polêmicas relacionados aos serviços prestados pelos motoristas parceiros que supostamente realizam o mesmo serviço que os taxistas. Sobre esta situação existem demandas judicias e projetos de lei tentando solucionar essa divergência. O presente trabalho investiga tributação sobre essa tecnologia, verificando quais tributos vigentes no país pode incidir sobre o serviço prestado pelo motorista, investigando ainda quais as formas de regulamentação e tributação segundo as ideologias existentes no Brasil, para a recepção desta tecnologia.
\end{abstract}

Palavras-chave: Aplicativo, Tributação, Uber

\begin{abstract}
The new technologies that are developed more easily bring to citizens, but can bring harm, such as the Uber app that is causing trouble and controversies related to the services provided by partners drivers who supposedly perform the same service as taxi drivers. About this situation there are judicial demands and bills trying to resolve this disagreement. This work investigates taxation on this technology, checking where existing taxes in the country may be imposed on the service provided driver, investigating further what forms of regulation and taxation according to the existing ideologies in Brazil, for the reception of this technology.
\end{abstract}

Keywords: Application, Taxation, Uber

\footnotetext{
${ }^{1}$ Atualmente é Procurador Federal - PGF/ADVOCACIA GERAL DA UNIÃO, (Brasil). E-mail: brunobiancoleal@hotmail.com

2 Mestrando pela Universidade de Marília, UNIMAR - SP , (Brasil).É advogado. E-mail: tancredo.thiago@gmail.com
} 


\section{INTRODUÇÃO}

O presente trabalho realiza uma pesquisa a respeito da tributação que poderá incidir sobre o aplicativo Uber e seu motorista por meio do ordenamento jurídico vigente, bem como das possibilidades e regulamentações que estão sendo criadas por projetos de lei e outras ideologias.

Este aplicativo vem causando vários problemas no Brasil, pois não existe nenhuma legislação vigente sobre sua regulamentação e a decorrente a comparação de seu serviço com o realizado pelos taxistas.

A pesquisa se justifica ao promover uma discussão sobre a recepção de novas tecnologias aplicadas no Brasil, como é o caso do serviço prestado pela Uber. Desta forma, é preciso averiguar quais os benefícios que o país poderá obter, principalmente na esfera tributária, demonstrando o que será arrecadado aos cofres públicos ao recepcionar o serviço realizado por esse aplicativo.

O Brasil possui uma das maiores cargas tributárias do mundo, motivo pelo qual existe a incidência de várias taxas, contribuições e impostos que irão ser cobradas deste aplicativo Uber, mesmo ainda não existindo uma regulamentação sobre esse tipo de atividade.

O objetivo principal desta pesquisa é proporcionar uma investigação de quais tributos poderão incidir sobre esse aplicativo disponibilizado por meio de um smartphone ou tablet, através do ordenamento jurídico recente, e também do projeto de lei em trâmite no congresso nacional, além da ideologia dos taxistas e da própria Uber sobre o pagamento dos tributos.

Compreendem-se como questão problema as lacunas existentes no ordenamento jurídico a respeito do tema, em razão de ser algo novo que possui semelhança a um serviço considerado exclusivo dos taxistas, todavia, realizada por aplicativo digital. Nesta perspectiva, questionasse quais os tributos poderiam incidir sobre esse aplicativo Uber e seu motorista parceiro, responsável pela realização do serviço.

Como hipótese, será realizada averiguação sobre o que vem a ser o serviço prestado por esse aplicativo segundo a própria empresa Uber, os taxistas e o projeto de lei 530/2015, por meio dessas informações será demonstrado quais os tributos incidirão sobre o motorista parceiro.

Para realização do trabalho é usado à metodologia de pesquisa qualitativa, por meio do método hipotético dedutível, promovendo uma investigação por meio de doutrinas, jurisprudências e demais periódicos. 


\section{POLÊMICA DO APLICATIVO UBER NO BRASIL}

Há poucos meses os meios de comunicação estão acompanhando, nas grandes capitais dos estados brasileiros, a guerra de transporte de passageiros entre os taxistas e os motoristas particulares que usam o aplicativo Uber.

Está discussão já chegou a um patamar que os taxistas estão agredindo pessoas que possuem veículos que se enquadram ao perfil dos motoristas Uber, no entanto, sem realmente saber se estão a serviço dessa empresa que disponibiliza o determinado aplicativo (HIGA, 2015).

Além disso, os sindicatos dos taxistas estão se mobilizando e promovendo demandas judiciais nas capitais em que o aplicativo esta sendo usado, argumentando uma concorrência desleal, bem como a inexistência de uma regulamentação legislativa sobre o seu serviço e também a falta de informações que explicitem quais tributos devem pagar.

$\mathrm{Na}$ concepção da Uber esse aplicativo é uma forma moderna e inovadora de prestar o serviço de transporte individual e particular pelo mundo, na qual é necessário apenas um smartphone ou tablet para obter o aplicativo, realizando um cadastro das informações pessoais e de um cartão de crédito para possuir o acesso a plataforma virtual que disponibilizará motoristas que poderão satisfazer a demanda dos usuários que buscam o serviço (UBER, 2015).

Em definições trazidas pelo Conselho Administrativo de Defesa Econômica (CADE) (ESTEVES, 2015) e pelo parecer jurídico de André Ramos Tavares (TAVARES, 2015, p. 21) mesmo pelo contrato de parceiro e de usuário do aplicativo, mostram a possibilidade de realmente funcionar esse aplicativo pelo mundo. Todavia, existem várias questões vagas que necessitam ser respondidas e regulamentadas, a respeito da legalidade da instituição desse aplicativo no país.

Isso é necessário principalmente em razão dos problemas existentes, em especial com os sindicatos de taxistas que estão revoltados com a concorrência desleal que vem sofrendo por meio dessa nova tecnologia estrangeira.

Percebe-se que existem vários temas a serem regulamentados a respeito desse aplicativo inovador que vem trazendo muitos problemas, principalmente com a concorrência 
dos táxis, bem como a preção sobre o legislativo federal, estadual e municipal, para abolirem ou regularem esse serviço.

\section{O QUE O BRASIL ESTÁ GANHANDO E O QUE PODERÁ GANHAR COM A REGULARIZAÇÃO DESSE APLICATIVO NA ESFERA TRIBUTÁRIA}

Por intermédio dessas conceituações e definições apresentadas, nos capítulos anteriores, pode-se começar a realizar uma análise tributária a respeito dos motoristas parceiros da Empresa Uber usando o aplicativo nas capitais dos estados brasileiros.

O presente trabalho não tem a objetivo apresentar de forma exata quais valores devem ser pagos por meio dos tributos pelos motoristas parceiros da Uber, mas quais desses deverão incidir no presente momento sem uma regulamentação sobre tal serviço.

Da mesma forma será também realizada uma investigação sobre quais os tributos incidiriam, se fosse realizada uma regulamentação segundo a ideologia fornecida pela própria Uber ou pelo Projeto de Lei 530/2015 que está em trâmite no Senado Federal, demonstrando quais tributos incidiriam sobre esse serviço.

\subsection{Motorista Parceiro}

Primeiramente, verifica-se a respeito do motorista parceiro da Uber desde a compra do veículo como uma pessoa comum que possui o interesse de vincular-se ao aplicativo, passando a analisar os tributos pagos por ele atualmente sem nenhuma devida regulamentação.

Posteriormente será realizada uma investigação dos meios de regulamentações existente no país para recepcionar este tipo de tecnologia, bem como a suas concepções sobre como tal serviço deve ser prestado e a forma de cobrança de tributos.

\subsubsection{A compra do veículo nos padrões Uber}

Ao verificar o motorista que utiliza o aplicativo, conforme exposto no capítulo anterior referente à concepção da Uber de que este é um simples parceiro, não possuindo vínculo empregatício, o mesmo é considerado sobre a os tributos a serem pagos. 
Esta concepção apresentada pela detentora dos direitos do aplicativo são as regras atualmente aplicadas, pelo fato de não existir nenhuma legislação ou regulamentação no país, dessa forma tais regras criadas pela Uber são as que devem ser obedecidas.

A ideia de parceiro da Uber é bem clara, segundo a empresa dona do aplicativo o parceiro é responsável por todas as despesas, a empresa somente disponibiliza o aplicativo e cobra a taxa referente ao uso. Portanto, questionasse: caso um cidadão brasileiro, que mora em São Paulo, interessado em tornar-se um motorista do aplicativo, comprando um veículo nos padrões exigidos pela Uber, quais tributos deveram ser pagos?

Desse modo, o motorista parceiro que comprará um veículo como qualquer cidadão, pagará todos os tributos que incidem normalmente sobre um veículo, como o IPI, ICMS, IPVA, COFINS, PIS, Taxa de Licenciamento do Veículo e o DPVAT.

Sobre uma concepção diferente, na qual é a ideologia dos taxistas e de suas demandas judiciais que afirmam que a Uber está realizando indevidamente o mesmo serviço privativo dos taxistas de transporte público individual.

No caso deste conceito regulamentado enquadrando o motorista parceiro, com os mesmos benefícios que os taxistas possuem, poderia existir várias isenções tributárias como do ICMS, IPI, IOF, ISS, IPVA, PIS e Cofins, fazendo assim que praticamente não possua o pagamento de tributos acima mencionados para compra do veículo, aumentando ainda mais, a concorrência desleal tão questionada pelos taxistas, pois com menos tributos, o motorista parceiro poderá conseguir uma estabilidade financeira muito maior.

Inclusive, poderá reduzir até mesmo as tarifas a ser paga pelos usuários, isso porque a Uber autorizar esta redução quando entender coerente, tal hipóteses está determinada no contrato com o motorista parceiro (TJSP, Ação Civil Pública nº 1054861-85.2015.8.26.0100 em Trâmite na $41^{\mathrm{a}}$ Vara Cível Foro Central Cível na p. 125).

Frente à ideologia a respeito da tributação, se realmente este aplicativo e seu serviço inovador trazido pela Uber se tornar uma atividade que se encaixe aos serviços privativos dos taxistas é possível que as isenções tributárias possam ser impostas aos parceiros desse aplicativo, trazendo ainda mais concorrência desleal com os serviços de táxi.

Sobre a compra do veículo acima analisado, o Projeto de Lei do Senado 530/2015 não apresenta nenhuma informação a esse respeito motivo pela qual mesmo sendo aprovado este projeto de lei, o motorista da Uber deve continuar pagando todos os tributos informados, o que é o mais correto, para não aumentar, ainda mais, a concorrência desleal. 


\subsubsection{O Motorista Parceiro e a Legislação e Tributação Atual}

A grande incógnita existente é como enquadrar esse motorista, considerado como pessoa física, nos tributos brasileiros, conforme já informado este não é funcionário da Uber, somente o considera como parceiro. Nesse sentido, a necessidade de regulamentação é urgente, para não continuar a ser considerado trabalhador informal, sem direito e deveres, principalmente tributários.

Mesmo não possuindo uma regulamentação ou descrição legal sobre a sua atividade, ainda assim deverá realizar o pagamento de tributos que incidirão pelo serviço realizado.

Diante deste pensamento pode-se iniciar uma análise por meio da legislação tributária em vigor, sobre quais os tributos que este motorista, trabalhando de forma autônoma e irregular, será obrigado a pagar.

Primeiramente, ao verificar a ideologia da Uber sobre o tipo de prestação de serviço que o parceiro realiza, já definida no capítulo anterior, pode-se afirmar que o serviço prestado é de transporte de passageiros de forma individual.

Este tipo de serviço é fácil de ser definido, isso porque o aplicativo realiza o vínculo entre o motorista e o passageiro, fazendo com que o passageiro seja transportado para onde deseja, diante disso existe um transporte de passageiros, que possui a incidência do Imposto sobre Serviços (ISS), descrito na Lei 116/03 em sua lista de serviço no ${ }^{\circ} 16.01$ que descreve que irá realizar o pagamento deste imposto por oferecer o serviço de transporte de natureza municipal.

A inexistência da palavra "passageiros" no item 16.01, não impede a incidência da cobrança do imposto, pois é possível interpretar que a forma descrita por tal item como genérica, ou seja, todos os transportes de natureza municipal deveram ser obrigatoriamente responsáveis pelo pagamento do Imposto sobre serviços, inclusive o de passageiros.

Ao realizar este tipo de serviço o motorista terá uma renda, segundo a empresa Uber, esta pode ser de $80 \%$ ou $75 \%$ do valor de cada transporte que realizar, depende da categoria na qual se encaixa. Através desses valores recebidos por meio eletrônico, em razão do pagamento do serviço pelo usuário ser por cartão de crédito (UBER, 2015), existirá a incidência do Imposto de Renda (IR), conforme descreve o art. 43 do Código Tributário Nacional: 
Art. 43. O imposto, de competência da União, sobre a renda e proventos de qualquer natureza tem como fato gerador a aquisição da disponibilidade econômica ou jurídica: I - de renda, assim entendido o produto do capital, do trabalho ou da combinação de ambos;

$[\ldots]$

$1^{\circ} \mathrm{A}$ incidência do imposto independe da denominação da receita ou do rendimento, da localização, condição jurídica ou nacionalidade da fonte, da origem e da forma de percepção.

Diante das informações apresentadas pelo artigo do CTN, fica clara a incidência deste imposto ao motorista parceiro, devendo ser demonstrada qual a base de cálculo deste imposto podendo ser o montante real, arbitrado ou presumido das rendas ou dos proventos tributáveis, conforme conceitua Sabbag "Adota-se, no Brasil, um critério de aferição de base de cálculo "pelo montante absoluto da renda ou provento" (critério global ou unitário), segundo o qual as alíquotas incidem sobre o total dos rendimentos, independentemente de sua origem ou razão" (SABBAG, 2013, p. 1213).

Por meio das informações apresentadas é necessário realizar a verificação das rendas e proventos que foram auferidas pelo motorista, para assim informar qual a sua base de cálculo e a alíquota, demonstrando, desse modo, qual o valor a incidir como Imposto de Renda.

Esta investigação pode ser considerada simples, em razão da forma de pagamento do motorista da Uber ser realizada por operação financeira de créditos, motivo pelo qual somente ao analisar a sua conta bancária, onde a empresa Uber realiza a transferência dos valores recebidos por ele pelo serviço prestado, já demonstra qual a base de cálculo das rendas adquiridas.

A respeito da questão do pagamento do usuário pelo serviço ser realizado por meio de operação financeira com o cartão de crédito, este ato faz com que exista a incidência do Imposto sobre Operações Financeiras (IOF), realizando o fato gerador descrito no art. 63, I do Código Tributário Nacional e no art. $2^{\circ}, \mathrm{I}$, “b” do Decreto $\mathrm{n}^{\circ} 6.306 / 07$, sobre a operação de crédito realizada pelo usuário ao pagamento do serviço prestado.

Isso acontece em decorrência ao pagamento do usuário ser enviada diretamente para a empresa Uber após a prestação do serviço, esta retira o percentual destinado de $20 \%$ ou $25 \%$, o restante transfere para a conta do motorista. Portanto, existe a incidência deste imposto em dois momentos.

Outro imposto que incidirá é o Imposto sobre a propriedade de veículos automotores (IPVA), em face da propriedade do veículo usada para prestar o serviço de transporte, descrito no art. 155, III da Constituição Federal. 
Além dos impostos apresentados, o motorista parceiro deverá realizar o pagamento de contribuição social, pelo fato de se enquadrar como um trabalhador autônomo, conforme define art. 12, V, "h" da Lei 8.213/91.

Diante de tais considerações o motorista parceiro é obrigado a realizar o pagamento da contribuição social previdenciária, como contribuinte individual.

Perante as informações expostas o motorista parceiro da Uber deverá realizar o pagamento dos seguintes impostos ISS, IRPF, IOF, IPVA e Contribuição Social.

Já as taxas que ele deverá pagar em face da falta de regulamentação é complexo afirmar quais são todas, todavia, como proprietário do veículo automotor é obrigado a realizar o pagamento da taxa para expedição do licenciamento do veículo obrigatório, para que seja emitido o licenciamento anual do veículo, conforme determinada pelo art. 130 e 131 do Código de Trânsito Brasileiro (CTB).

Existe também a incidência do Seguro de Danos Pessoais Causados por Veículos Automotores de Via Terrestre (DPVAT), descrito no Decreto Lei $n^{\circ} 73 / 66$, no entanto não é considerada uma taxa, mas sim uma contribuição parafiscal (Supremo Tribunal de Justiça. RESP N 68.146. Relator ministro Carlos Alberto Menezes Direito, Brasília, 10 de fevereiro de 1998), que deverá obrigatoriamente ser paga todos os anos para ter direito ao licenciamento do veículo conforme a portaria do departamento de trânsito acima citado.

Estes são os tributos obrigatórios segundo a legislação tributária brasileira que deverão incidir ao motorista parceiro da Uber como contribuinte. Em face da não existência de uma regulamentação, a incidência de tais tributos existe em razão da descrição da atividade realizada pelo motorista parceiro e o ordenamento jurídico brasileiro que possui perfeitamente informações e descrições passíveis da aplicação destes tributos a essa nova tecnologia que está causando polêmica no Brasil.

Todavia, na concepção da empresa Uber independente da forma que o parceiro é enquadrado como figura jurídica, todos os tributos que forem cobrados, mesmo que em uma futura regulamentação reconheça o seu vínculo empregatício com a startup de tecnologia, será sempre isenta de todos os pagamentos, sendo descontado tais impostos, taxas e contribuições sócias direitas da remuneração do parceiro, ou seja, dos $80 \%$ ou $75 \%$ do valor de cada transporte de pessoas indicado pela Uber (TJSP, Ação Civil Pública n ${ }^{\circ}$ 105486185.2015.8.26.0100 em Trâmite na 41ª Vara Cível Foro Central Cível na p. 27). 
Mais uma vez a Uber simplesmente restringe toda a sua responsabilidade, declarando que a sua função é somente de disponibilizar o aplicativo e nada mais, tornando assim o motorista parceiro responsável por todos os tributos vinculados a ele em caso de um futuro suposto vinculo empregatício.

No entanto, no presente momento o motorista parceiro da Uber é considerado um trabalhador autônomo, responsável por pagar os tributos acima descritos, não sendo qualificado como um empregado da empresa detentora dos direitos do aplicativo, sendo a melhor solução, até o presente momento para fins tributários e de arrecadação aos cofres públicos.

\subsubsection{O Motorista Parceiro e as Possíveis Formas de Regulamentações e Tributação}

A partir desse momento realiza-se uma investigação da possível regulamentação que poderá ser criada para esse aplicativo e o motorista parceiro que realiza o transporte individual de passageiros, sendo analisado por meio do Projeto de Lei 530/2015 e sobre a concepção dos motoristas de táxi que sua ideologia trazida por meio das ações trabalhistas que tramitam pelo Brasil, para decretar este aplicativo como irregular.

Seria possível além dessas duas formas apresentadas, tratar da concepção da Uber como um modelo de regulamentação, todavia, no capítulo anterior já demostramos as suas regras que indevidamente estão sendo aplicadas no país atualmente, por essa razão serão tratados somente o projeto de lei e a ideia dos taxistas.

Segundo o Projeto de Lei $\mathrm{n}^{\circ}$ 530/2015, proposto pelo Senador Ricardo Ferraço, em trâmite do Senado Federal, tenta regularizar o serviço deste aplicativo dentre outras determinações, apresenta em seu art. $3^{\circ}, \S 2^{\circ}$ a seguinte determinação:

Art. $3^{\circ}$ As PRCs não se qualificam como empresas prestadoras de serviços de transporte, não se confundindo, portanto, como prestadores de serviço público individual de transportes.

$\S 2^{\circ}$ Todos os motoristas-parceiros deverão estar enquadrados nas figuras jurídicas do Microempreendedor Individual (MEI) ou no Simples Nacional como requisito para ingresso na plataforma.

Portanto, o parceiro deverá buscar o seu cadastro como Microempreendedor Individual ou no Simples Nacional, para conseguir realmente ser tornar um motorista parceiro da Uber no Brasil. 
Sendo uma pessoa jurídica enquadrada como Microempreendedor Individual (MEI) ou no sistema do Simples Nacional, que são formas de regulamentação diferenciadas aos empresários, modalidades introduzidas no Brasil em razão da crise financeira internacional e também o combate a grande quantidade de pessoas que trabalham informalmente no Brasil (MARTINS, 2014, p. 430).

A Lei Complementar 128/2008, apresenta no art. 18-A a opção de recolhimento dos impostos e contribuições pelo Simples Nacional por meio de valores fixos mensais, independentemente dos seus rendimentos do mês, desde que respeitados alguns limites descritos em seus parágrafos para se tornar um MEI.

Em razão do parceiro Uber, ainda não possuir regulamentada específica, as regras a seu respeito são as mesmas dispostas no caput do art. 18-A da Lei Complementar 123/06 que descreve as regas do MEI, neste artigo em seu $\S 2^{\circ}$, descreve a receita bruta máxima que pode ser auferida por ele, que é de $\mathrm{R} \$ 5.000,00$ (cinco mil reais) mensais, multiplicado pelos meses do início da atividade e o final do mesmo ano.

Não sendo os valores superiores a estes $\mathrm{R} \$ 5.000,00$ ao mês, poderá ser o motorista parceiro enquadrado como Microempreendedor Individual, tendo assim uma tributação diferenciada, pagando os seguintes tributos em razão do serviço de transporte que realiza.

A Lei 123/06 no seu artigo $2^{\circ}$, inciso I e no $§ 6^{\circ}$, autoriza ao Comitê Gestor do Simples Nacional (CGSN) regulamentar por meio de resoluções assuntos dessa mesma lei complementar, principalmente sobre tributação, fiscalização, arrecadação e outras disposições, como forma de atualizar os valores e informações que o CGSN entenda pertinente.

Por meio dessas resoluções, sendo a mais recente e atualmente usada a $n^{\circ} 94 / 2011$, no seu artigo 92 determina o que deverá ser pago mensalmente pelo parceiro da Uber como forma de impostos e contribuições.

Segundo inciso I, deverá ser pago $5 \%$ do limite mínimo mensal do salário de contribuição como Contribuição Social. Também deverá pagar R \$ 5,00 (cinco reais) de Imposto sobre Serviços (ISS), como determina o inciso II do mesmo artigo.

A respeito do ISS o Projeto de Lei 530/2015, já mencionado reforça o entendimento de deverá ser pago este imposto pelo parceiro da Uber em seu artigo $3^{\circ}, \S^{\circ}$, aplicando os mesmo parâmetros do serviço de taxi, todavia na maioria dos municípios aplicam a isenção aos taxistas a respeito deste imposto, e ainda, conforme demonstrado caso ele seja enquadrado como 
MEI deverá somente pagar os tributos descritos na lei complementar acima mencionada, portanto poderá existir um conflito de normas a esse respeito.

Esses são impostos e contribuições sócias que o motorista parceiro da Uber deverá pagar caso seja qualificado como microempreendedor individual, essa categoria é diferente, pois independente de quanto receba até um valor de anual de $\mathrm{R} \$ 60.000,00$ (sessenta mil reais), continuará pagando o mesmo valor fixo destes tributos, conforme determina o art. 91 da Resolução 94/2011 e a Lei Complementar 123/2006.

A única questão a ser analisada a respeito do MEI, é quanto ao Imposto de Operações Financeiras (IOF) que não é descrito no Projeto de Lei 530/2015 como aplicado, no entanto no art. 14 deste projeto de lei determina que seja realizado o pagamento do serviço por meio de Provedor de Rede de Compartilhamento, sendo proibido o pagamento direto entre o parceiro da Uber e o usuário, bem como por meio de dinheiro.

As regras do projeto de lei são idênticas as do contrato de usuário e parceiro da Uber, conforme já informado anteriormente, devendo ser feito o pagamento por meio de operações de cartão de crédito, conforme já demonstrado anteriormente. Diante disso, compreende-se a possibilidade de incidência do IOF nesta operação financeira nos mesmos moldes descritos no subcapítulo anterior.

Além disso, na Lei Complementar 123/06 em seu art. 18-A, precisamente no $§ 3^{\circ}$, IV, dita que é possível a aplicação dos impostos do art. 18-C dependendo do serviço que é prestado, autorizando a aplicação do IOF no inciso I do $\S 1^{\circ}$ deste artigo.

Da mesma forma, conforme mencionado no subcapítulo anterior que trata da tributação que incide atualmente, existirá a incidência anual do imposto sobre a propriedade de veículos automotores (IPVA), em face da propriedade do veículo do motorista parceiro.

Diante dessas considerações, pode-se afirmar que por meio da análise do projeto de lei 530/2015 a respeito do serviço prestado pelo parceiro da Uber é pago os seguintes tributos como microempreendedor individual: Contribuição Social, ISS, IOF e IPVA.

Após exaurir a modalidade empresarial de microempreendedor individual, começa a verificar como seria a tributação paga pelo motorista parceiro que opta pela tributação diferenciada concedida pelo Simples Nacional.

Sobre essa tributação é apresentada a própria lei complementar 123/06, apresenta a forma de tributação das microempresas e empresas de pequeno porte que optem pelo Simples Nacional, no artigo 18 informa que será aplicada alíquotas por meio de tabelas em anexo a lei complementar sobre a base de cálculo a receita bruta auferida no mês. 
A respeito do serviço prestado pelo parceiro da Uber, existe um consenso de como qualificar o serviço, visto que o projeto de lei e os taxistas o compreendem como serviço de transporte municipal de passageiros.

Por meio dessa qualificação, o art. 18, §5-B informa que os serviços descritos em seus incisos deverão ser tributados na forma da tabela do anexo III da Lei Complementar 123/06, sendo que dentre estes inciso, precisamente no XIII descreve o serviço de transporte municipal de passageiros.

Nessa perspectiva, passamos analisar quais os tributos aplicados a este serviço aqui caracterizado como o realizado pelo parceiro da Uber, segundo a tabela incidirão: IRPJ, CSLL, COFINS, PIS, CPP e ISS.

A tabela que apresenta a incidência destes tributos é progressiva, informando a base de cálculo e as alíquotas que incidirão nos valores declarados anualmente pelo contribuinte, a primeira base de cálculo um valor de até $\mathrm{R} \$ 180.000,00$ (cento e oitenta mil reais) por ano, possuindo os tributos acima mencionados com as seguintes alíquotas o ISS com $2 \%$, CPP com $4 \%$ e o restante como o IRPJ, CSLL, COFINS e PIS, todos com alíquota $0 \%$.

Dessa forma, existirá somente a incidência de $6 \%$ sobre o valor anual recebido pelo parceiro da Uber, caso seus rendimentos não ultrapasse $\mathrm{R} \$ 180.000,00$ (cento e oitenta mil reais), a respeito das alíquotas de $0 \%$, é oportuno trazer algumas considerações a seu respeito, pois é definida com uma alíquota nula, trazendo um tributo sem qualquer expressão econômica, dessa forma mesmo ocorrendo o seu fato gerador, o valor a ser apurado será zero (PAULSEN, 2014, p. 263).

Tal medida é realizada com o mesmo fundamento da existência do microempreendedor individual e do sistema do simples nacional, ou seja, querendo incentivar certas atividades o poder executivo, opta por diminuir a alíquota de alguns tributos a zero (ALEXANDRE, 2015, p. 157).

Diante dessas considerações, existe o fato gerador e a incidência do tributo, todavia como sua alíquota é zero, o valor a ser cobrado do contribuinte é nulo, isso mostra que o tributo existe, podendo futuramente alterar a sua alíquota fazendo com exista a sua incidência.

Além dos tributos acima descritos, a forma de pagamento do serviço é obrigatoriamente feito por operação financeira por intermédio de um cartão de crédito, como já demostrado, o mesmo ocorre com o simples nacional, devendo assim incidir o IOF conforme dita o art. $13, \S 1^{\circ}$, inciso I da lei $123 / 2006$. Esta forma de pagamento é a única autorizada pela empresa a Uber e o projeto de Lei 530/2015. 
Deverá também incidir sobre o motorista da Uber o pagamento do Imposto sobre a propriedade de veículo automotor, descrito no art. 155, III da Constituição Federal, em razão da propriedade do veículo utilizado para a prestação do serviço.

A investigação a respeito do Simples Nacional disposto na lei complementar 123/2006, onde ele deverá ser enquadrado no Simples Nacional.

Diferente do descrito no contrato entre a Uber e o motorista parceiro já anteriormente analisado, considerado a forma atual da prestação deste serviço, o projeto de lei 530/2015, apresenta a melhor solução para a regularização deste trabalhador, pois cria obrigações, mas também direitos ao transformá-lo em um microempreendedor individual ou enquadrá-lo como no simples nacional. Essas propostas favorecem a nova profissão, como também auxiliam o país a regularizar e fiscalizar o aplicativo, os motoristas e os usuários, além de arrecadar dinheiro aos cofres públicos por meio da tributação.

Tudo que foi exposto demonstra quais as contribuições sociais e os impostos que podem ser pagos pelo motorista. Todavia, existem taxas que serão aplicadas a esses motoristas, ou seja, sobre esse motorista parceiro, pois o mesmo é responsável por todos os tributos, incluindo as taxas. Dessa forma, compreende-se como necessário uma regulamentação que demostre de modo específico às taxas que irão incidir sobre o motorista que se enquadra nesse determinado serviço.

No entanto, em conformidade a ideia dos taxistas que consideram que a Uber realiza o mesmo serviço eles, neste caso deverá incidir as mesmas taxas pagas pelos taxistas. A título de exemplo, é oportuno descrever as taxas pagas pelos taxistas no município de São Paulo, segundo a lei 7.329/69 deverá ser pagas:

Art. 40 - Os permissionários ficam sujeitos s seguintes taxas:

I - De Licença para Estacionamento de Veículos, anual, relativa ao veiculo que estacione em:

a) ponto privativo - $20 \%$ (vinte por cento) do valor do salário mínimo;

b) ponto livre - $10 \%$ (dez por cento) do valor do salário mínimo.

II - De Expediente, referente a:

a) inscrição, ou sua revalidação, no Cadastro Municipal de Condutores de Táxis $2 \%$ (dois por cento) do valor do salário mínimo;

b) registro para condutor de veiculo de propriedade de terceiros $10 \%$ (dez por cento) do valor do salário mínimo;

c) alvará de estacionamento ou sua renovação - NCr\$ 5,00 (cinco cruzeiros novos);

d) termo de permissão para empresa - $50 \%$ (cinquenta por cento) do valor do salário mínimo;

Pelo artigo exposto, o motorista parceiro deverá pagar na cidade de São Paulo a taxa de Cadastro Municipal de Condutores e a licença para estacionamento de veículos, como 
condições para permissão municipal de trafegar e prestar o serviço de transporte de passageiros municipal na cidade de São Paulo.

Já na concepção do projeto de Lei $\mathrm{n}^{\circ}$ 530/2015, em seu art. $4^{\circ}$, determina que a responsabilidade de fiscalização da Uber e também do motorista parceiro é realizada pelo órgão municipal de trânsito e transporte, respeitando a lei municipal, bem como a competência para instituir taxas de licenciamento anual, devendo ser revertido seus valores em obras, investimentos e programas de melhoria ao desenvolvimento urbano e ao transporte público. E, ainda no mesmo artigo no $\S 2^{\circ}$, determinam que estas taxas não devam ser inferiores as cobradas ao serviço de táxi.

Parece que as regras apresentadas pelo projeto de lei são as mais claras e sensatas, delegando a responsabilidade pelas taxas a serem pagas ao município, principalmente a respeito da fiscalização que é muito mais eficiente do que do estado e da união.

Percebe-se que as regras dos taxistas são semelhantes as do projeto de Lei, sendo que este último tomou o cuidado de informar o valor das taxas aplicadas a Uber e seu motorista, essas não podem ser inferiores à cobrada aos táxis, isso é feito para reduzir a concorrência desleal argumentada pelas taxistas.

Nesse sentido, compreende-se que para o motorista da Uber existe à taxa para a expedição do licenciamento do veículo, uma condição para expedição do licenciamento anual do veículo, já descrita anteriormente e a incidência do Seguro de Danos Pessoais Causados por Veículos Automotores de Via Terrestre (DPVAT), considerado como uma contribuição parafiscal (Supremo Tribunal de Justiça. RESP N ${ }^{\circ}$ 68.146. Relator ministro Carlos Alberto Menezes Direito, Brasília, 10 de fevereiro de 1998), que deverá obrigatoriamente ser paga todos os anos.

Ambas as taxas são obrigatórias para motorista parceiro conseguir o licenciamento do veículo, um requisito imprescindível para trafegar pelo território brasileiro, principalmente para o motorista da Uber, pois de acordo com o projeto de lei já citado anteriormente, caso não possua o licenciamento, não poderá ser um motorista parceiro.

Ao realizar a investigação a respeito dos tributos a serem pagos pelos motoristas parceiros da Uber, na concepção da própria empresa detentora dos direitos do aplicativo que atualmente é a forma que é exercida esta atividade, através do contrato de parceria entre esta e o motorista e o contrato com o usuário.

Também sobre a investigação das ideologias trazidas pelos taxistas e do Projeto de Lei 
530/2015, pode-se chegar à conclusão que para o Brasil como forma de arrecadação e para melhor solução do conflito da empresa com os taxistas, o projeto de lei é melhor forma de regulamentação, mesmo existindo alguns problemas e omissões, é possível aplicar tal lei para regulamentar tal tecnologia no país.

Isso porque as regras descritas pela Uber em seu contrato de parceiro e usuário que estão sendo aplicadas no Brasil ao ser prestado esse serviço, não é a forma mais sensata e correta segundo o ordenamento jurídico brasileiro, diferentemente do que é feito pelo projeto de lei que apresenta uma mesma concepção do objetivo da Uber, todavia com adequação a legislação brasileira.

Por meio disso não se fecha as portas do país para as novas tecnologias e inovações do exterior, porém demonstra a estas empresas e multinacionais que a leis brasileiras são soberanas e para que tais serviços inovadores sejam aplicados neste território é necessário adequação.

Ainda a respeito de o país recepcionar estas novas tecnologias e as tributar, sem uma regulamentação concreta, uma das saídas buscadas na Europa, especificamente pela Estónia, foi a de criar uma parceria entre a Uber e Conselho Fiscal e Aduaneiro da Estônia, como finalidade de demonstrar as maneiras de aplicar a tributação nesta nova forma de transporte (AASMÄE, 2013).

O objetivo deste vínculo não é somente de criar a regulamentação do aplicativo do país, mas também demonstra a possibilidade de enfrentar o desafio de receber novas formas de tecnologias digitais e regulamentá-las, principalmente a respeito de tributação.

Por essa razão, diante de todas as informações apresentadas a melhor regulamentação a ser aplicada no presente momento é a do projeto de lei 530/2015, todavia a forma de parceria entre o país Europeu e a Uber, também pode trazer várias soluções aos conflitos e melhorar a regulamentação.

Portanto, é uma questão de acordo entre a tecnologia e o Brasil, para que ambos possam de forma clara e concreta criar uma regulamentação satisfatória para ambos, trazendo por parte do país um projeto de lei como o 530/2015, do outro lado a Uber ao demonstrar ideias que melhorem o projeto e que faça com que a relação entre ambos traga uma melhor solução para a aplicação desta tecnologia digital em favor do usuário e do motorista parceiro. 


\section{CONSIDERAÇÕES FINAIS}

Por meio da pesquisa realizada é possível compreender que está nova tecnologia tem causado grande polêmica pelo fato de criarem novos tipos de concorrência aos taxistas, visto que anteriormente tinham a exclusividade na prestação deste serviço.

Todavia, o Brasil não pode deixar de recepcionar este tipo de aplicativo tecnológico, isso porque não será a primeira, nem a última vez que essa situação irá ocorrer, em razão do crescimento de novas plataformas e aplicativos digitais, criados para trazer mais comodidade e acessibilidade a serviços e recursos.

Nesse sentido, a Uber proporciona facilidade a seus usuários, trazendo mais comodidade para o acesso ao prestador do serviço, ou seja, o motorista parceiro, pelo fato de informar todas as qualificações daquela pessoa que irá realizar o transporte. Essa proposta possibilita inovações e acaba por ultrapassar a forma de prestação de serviço antiga.

As concepções trazidas pelos taxistas contra este aplicativo, por meio de demandas judiciais, compreendem a criação de um retrocesso tecnológico ao Brasil, principalmente no aspecto tributário, pois restringindo as inovações fará com que não existe nenhuma arrecadação aos cofres públicos na realização deste novo serviço.

Por meio da pesquisa realizada no presente trabalho, é possível averiguar que existem tributos a serem pagos pelos motoristas parceiros, todavia a melhor solução no presente momento sobre este problema a respeito do aplicativo Uber, principalmente na ótica tributária, é instituir uma lei que recepcione tal aplicativo regulamentando a atividade do motorista parceiro, nos moldes do projeto de lei 530/2015.

Além disso, para melhor aplicabilidade é possível tentar fazer com que a Uber seja chamada para discutir tais normas promovendo assim melhor debate para trazer soluções para a recepção deste aplicativo no Brasil.

Mesmo existindo algumas lacunas e problemas com outras normas jurídicas, compreendem-se, estas concepções apresentadas, como as melhores formas de regulamentação existente no país, ao trazer informações sobre a forma do serviço e a fiscalização sobre o motorista parceiro da Uber.

Portanto, em conformidade a ideologia do direito tributário e dos ganhos proporcionados ao Brasil com a regulamentação deste aplicativo o projeto de lei, em trâmite no senado, sugere a relevantes estratégias de regulamentação a respeito do serviço prestado por essa tecnologia de transporte privado. 


\section{REFERÊNCIAS}

AASMÄE, Mailin. ETCB and Uber collaborate in seeking solutions for the development of the sharing economy. Estônia. [s.d]. Disponível em: $<$ http://www.emta.ee/index.php?id=37605\&tpl=1026>. Acesso em 15. nov. 2015.

ALEXANDRE, RICARDO. Direito tributário esquematizado. Rio de Janeiro: Método, 2015.

BRASIL, Constituição do. Constituição da República Federativa do Brasil. Disponível em: < http://www.planalto.gov.br/ccivil_03//Constituicao/Constituicao.htm >. Acesso em: 28 out. 2015.

, Decreto-lei $\mathrm{n}^{\circ}$ 73, de 21 de novembro de 1966. Dispõe sôbre o Sistema Nacional de

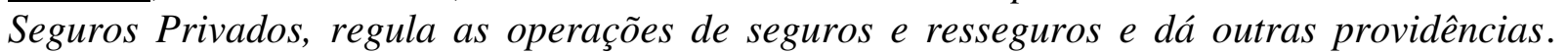
Disponível em: < http://www.planalto.gov.br/ccivil_03/decreto-lei/Del0073.htm>. Acesso em: 05 nov. 2015.

, Decreto $\mathrm{n}^{\circ}$ 6.306, de 14 de novembro de 2007. Regulamenta o Imposto sobre Operações de Crédito, Câmbio e Seguro, ou relativas a Títulos ou Valores Mobiliários IOF. Disponível: < http://www.planalto.gov.br/ccivil_03/_Ato20072010/2007/Decreto/D6306.htm >. Acesso em: 28 out. 2015.

, Lei complementar $\mathrm{n}^{\circ} 123$, de 14 de dezembro de 2006. Institui o Estatuto Nacional da Microempresa e da Empresa de Pequeno Porte; altera dispositivos das Leis no 8.212 e 8.213, ambas de 24 de julho de 1991, da Consolidação das Leis do Trabalho - CLT, aprovada pelo Decreto-Lei no 5.452, de 1 o de maio de 1943, da Lei no 10.189, de 14 de fevereiro de 2001, da Lei Complementar no 63, de 11 de janeiro de 1990; e revoga as Leis no 9.317, de 5 de dezembro de 1996, e 9.841, de 5 de outubro de 1999. Disponível em: < http://www.planalto.gov.br/ccivil_03/leis/LCP/Lcp123.htm>. Acesso em: 02 out. 2015.

Lei complementar $\mathrm{n}^{\circ} 128$, de 19 de dezembro de 2008. Altera a Lei Complementar no 123, de 14 de dezembro de 2006, altera as Leis nos 8.212, de 24 de julho de 1991, 8.213, de 24 de julho de 1991, 10.406, de 10 de janeiro de 2002 - Código Civil, 8.029, de 12 de abril de 1990, e dá outras providências. Disponível em: < http://www.planalto.gov.br/ccivil_03/leis/LCP/Lcp128.htm>. Acesso em: 20 out. 2015. Acesso em: 20 out. 2015.

Lei $\mathrm{n}^{\circ}$ 5.172, de 25 de outubro de 1966. Dispõe sobre o Sistema Tributário Nacional e institui normas gerais de direito tributário aplicáveis à União, Estados e Municípios. Disponível em:< http://www.planalto.gov.br/ccivil_03/Leis/L5172.htm >. Acesso em: 24 out. 2015.

, Lei $\mathrm{n}^{\circ}$ 8.213, de 24 de julho de 1991. Dispõe sobre os Planos de Benefícios da Previdência Social e dá outras providências. Disponível em : <http://www.planalto.gov.br/ccivil_03/leis/L8213cons.htm>. Acesso em 02 de nov. 2015. 
Lei $\mathrm{n}^{\circ}$ 9.503, de 23 de setembro de 1997. Institui o Código de Trânsito Brasileiro. Disponível em: < http://www.planalto.gov.br/ccivil_03/LEIS/L9503.htm >. Acesso em: 04 nov. 2015.

$\begin{array}{cccc} & \text { Lei }{ }^{\circ} 10.833, \text { de } 29 \text { de dezembro de 2003. Altera a Legislação Tributária Federal e } \\ \text { outras } & \text { providências. } & \text { Disponível } & \mathrm{em}:\end{array}$ http://www.planalto.gov.br/ccivil_03/leis/2003/L10.833.htm>. Acesso em: 05 nov. 2015.

Projeto de Lei do Senado $\mathrm{n}^{\mathrm{o}} 530$ de 2015. Institui a lei que regulamenta e organiza o sistema de transporte privado individual a partir de provedores de rede de compartilhamento e insere o inciso XIV ao artigo 4 da Lei 12.587/2012, de forma a definir a modalidade. Disponível em: http://www.senado.leg.br/atividade/rotinas/materia/getPDF.asp?t=173659\&tp=1>. Acesso em: 19 out. 2015

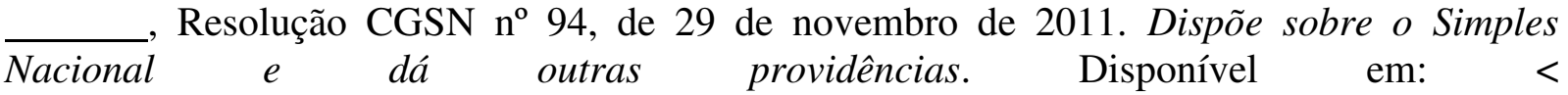
http://www.normaslegais.com.br/legislacao/resolucao-cgsn-94-2011.htm >. Acesso em: 20 out. 2015.

Supremo Tribunal de Justiça. RESP $N^{\circ}$ 68.146. Relator ministro Carlos Alberto Menezes Direito, Brasília, 10 de fevereiro de 1998. Disponível em < https://ww2.stj.jus.br/processo/ita/documento/mediado/?num_registro=199500300621\&dt_pu blicacao=17-08-1998\&cod_tipo_documento=\&formato=PDF $>$. Acesso em: 12 nov. 2015.

ESTEVES, Luiz Alberto. O mercado de transporte Individual de Passageiros: Regulação, Externalidades e Equilíbrio Urbano. Brasília: Departamento de Estudos Econômicos - DEE, 2015. Disponível em: <http://www.cade.gov.br/upload/O\%20Mercado\%20de\%20Transporte\%20Individual\%20de \%20Passageiros.pdf> Acesso em: 09 out. 2015.

HIGA, PAULO. Taxistas ameaçam Uber: "já furei dois pneus, arranquei o passageiro de dentro do carro". Tecnoblog, 13 jul. 2015. < https://tecnoblog.net/181336/taxistas-uberameacas/>. Acesso em: 15 out. 2015.

MARTINS, FRAN. Curso de direito comercial. Rio de Janeiro: Forense, 2014.

PAULSEN, LEANDRO. Direito Tributário Constituição e Código Tributária à luz da doutrina e da jurisprudência. Rio Grande do Sul: Livraria dos Advogados, 2014, p. 263.

SABBAG, Eduardo. Manual de direito tributário. São Paulo: Saraiva, 2014.

, Lei $\mathrm{n}^{\circ} 7.329$, de 11 de julho de 1969. Estabelece normas para execução de serviço de transporte individual de passageiros em veiculos de aluguel taxímetro, e dá outras providencias. Disponível em: $<$ http://www.prefeitura.sp.gov.br/cidade/secretarias/transportes/institucional/index.php?p=699 7>. Acesso em 02 nov. 2015. 
Tribunal de Justiça do Estado de. 41 a Vara Cível Foro Central Cível. Ação Civil Pública $n^{o}$ 1054861-85.2015.8.26.0100. Instaurado em 08 jun. 2015. Disponível em:<https://esaj.tjsp.jus.br/cpopg/show.do?processo.codigo=2S000H0YA0000\&processo.for $\mathrm{o}=100>$. Acesso em: 03 nov. 2015.

UBER B. V. Termos do usuário. Brasil, 2015. Disponível em < https://www.uber.com/legal/bra/terms>. Acesso em: 16 set. 2015.

Como registro meus dados bancários para receber os ganhos de viagens? São Paulo, [s.d]. Disponível em: <http://www.parceirossp.com/preccedilos.html> Acesso em: 15 out. 2015.

Políticas de preços transparente. São Paulo, [s.d]. Disponível em:

<http://www.parceirossp.com/preccedilos.html> Acesso em: 15 out. 2015.

TAVARES, André Ramos. Parecer Jurídico. São Paulo, 2015. Disponível em: < http://www.parceirospoa.com/uploads/5/4/7/6/54769587/_kit_doc_01.pdf>. Acesso em: 22 out. 2015. 